sciendo

Philosophy in the Twentieth Century: a Revolutionary Path

Charles Travis

Stirling University

Disputatio No. 8

May 2000

DOI: $10.2478 /$ disp-2000-0001

ISSN: 0873-626X 
Disputatio 8, May 2000

\title{
PHILOSOPHY IN THE TWENTIETH CENTURY: A REVOLUTIONARY PATH
}

\author{
Charles Travis
}

The millenium is daunting. My more modest topic is a century. It is conceivable that its most important philosophical event will take place between now and December 31. But it is unlikely. So we are at a point where we can, not unreasonably, assess the sort of century philosophy has had. A good one would have revolutionary moments, at which thinking about problems, and about philosophy itself, changed radically. Two revolutions in a century would be a lot. I will describe what I think is the crucial one in ours.

The view I will present may, to some, seem biased. First, I do not think that the revolution means that philosophy is, or should be, at an end, that we are somehow in a period of 'post-philosophy', or that the idea of a philosophical problem is somehow passé. The revolution I am going to describe left some genuine, and severe, problems. At the end of my talk I will describe them, and hint, but no more, at a way with them-one I do not know to be adequate, since it has not yet been tried fully. Second, it will occur to some of you that my revolution is suspiciously Anglophone, so, perhaps, parochial. If 'Anglophone' includes enough of Vienna and Berlin, and enough work written in German, then my revolution is, indeed, Anglophone. Given the political events of our century, it is not surprising that that should be so. In any event, such is life. If I thought the action were elsewhere, I would be there.

The revolution I have in mind can be dated as occurring between 1930 and 1960. That is a period that opened with the start of Wittgenstein's lecturing at Cambridge (roughly coincident with his new approach to philosophy), and ended with J. L. Austin's death-a period I am construing as broad enough to capture two other key revolutionary figures, Hilary Putnam and Noam Chomsky. (Stuart Hampshire, in his memoriam, said of Austin, "He could not have adopted a special tone of voice, or attitude of mind, for philosophical questions." That attitude towards philosophy-what I would call good faith-encapsulates the revolution.)

\footnotetext{
"Talk delivered on November 18, 1999 as the Marshall M. Weinberg Annual Lecture at the University of Michigan.

${ }^{1}$ Stuart Hampshire, "In Memoriam J. L. Austin 1911-1960", Proceedings of the Aristotelian Society, N. S. Vol. 60, 1959-1960, pp. I-ii.
} 
I face one serious worry. Some of my colleagues may think that the real important revolution in the twentieth century happened somewhat earlier than mine. They would be apt to mention Russell, and Wittgenstein before his change of approach, as at its center. Now, I agree that those figures were at the center of an important revolution. But, as I see things, that was a nineteenth century revolution-indeed, that century's most important one-begun by Frege in 1879. My twentieth century revolution is, in large part, though not just, a reaction against just the features of this earlier one that most exercised Russell and early Wittgenstein. Some, of course, will find that reaction unfounded. That is a controversy into which I plan to enter in what follows.

\section{EMPIRICISM}

The twentieth century revolution has two main parts. It is a rejection of empiricism; and it is a rejection of a certain form of Platonism (as we shall see, engendered by the Fregean revolution mentioned above). I will be more concerned in this lecture with the anti-Platonism, and its consequences. But I want to touch on the anti-empiricism, since it is crucial for philosophical method.

The core of empiricism, in the present sense, is a two pronged thesis: first, there is a privileged class of facts; second, there is a determinate topic neutral set of knowledge-yielding means: principles, procedures or methods. A given empiricism claims to be able to identify those facts, and those means, in advance of inquiry in any given field (that is, topic-neutrally). The key idea is that any fact is answerable to the privileged ones via the specified means. An empiricist will usually tell us that some significant domain of what we thought fact fails to answer, or does not answer as we thought it did; so it consists either of no real facts at all, or of not the facts we thought there were.

Answerability is, au fond, the idea that for any genuine way we might think of things as being, it must be possible for someone who does not know what that way is to come to know it-what it is for things to be that way-by applying specified means to given areas of privileged fact. So either what it is for something to be that way is for the privileged facts to be arranged in such and such way, or at least the only real grounds there could be for taking things to be the way in question is that the privileged facts are arranged in such and such ways. So, for example, there is such a thing as a person's being happy only if someone who did not know what it was for someone to be happy could (in principle) come to know this by extrapolating from the privileged facts by the specified means. (I assume here that facts of happiness themselves are not among the privileged.)

To be slightly less abstract, privileged facts are usually meant to be those we actually confront in experience- - those it is open to us just to observe. To repeat, the empiricist thinks these are a definite class of fact, and he can say (in advance of confronting experience) which ones they are. He might tell us, for example, 'all we can really observe about others is their behavior', or 'all 
we can really observe is the way things appear to us.' An empiricist's idea of the observable usually rests on some version of what is called a 'highest common factor argument'. The argument turns on this thought. Suppose as far as you can tell things are a given way, and, in fact, they are that way. Now suppose there is a possible situation in which things are not that way, and such that, were you in it, everything would seem just the same to you-you could not notice any deviation from the situation you in fact are in. Then all you can really observe, in either situation, is what is in common to both. So, for example, Pia is exuding happiness. You see her beaming and fluttering with it. Or so you think. But, in principle, there could be a highly trained actress whose performance was indistinguishable from Pia's joy, though produced utterly cynically and with a bitter heart. Her performance could look as much like Pia's happiness as you like. So, the argument concludes, all you really observe about Pia are (at most) flutterings and beamings. The rest is inference.

If you behaved badly last night, that consisted in your insulting Pia, or making overly suggestive remarks, or leering or whatever it is you did. If your behavior consisted in merely making noises, that contrasts with making conversation, and is bad enough in its own right. That is our ordinary concept of behavior. If we stick to it, then the idea that what you observe about others is their behavior does not threaten our ability to see that Pia is happy. If we hear your insults and see your leers, what bars us from seeing happiness? To threaten that, we need a proprietary notion of behavior. The highest common factor argument promises to supply just that.

Empiricism purports to place an a priori and substantive requirement on genuine facts, or fact-stating: its requirement of answerability. In Philosophical Investigations $\$ 136$, Wittgenstein rejects the idea that there can be any such requirement. That is a cornerstone of his later philosophy, and of the twentieth century revolution. It is a foundation of Austin's attacks on particular empiricisms. As that rejection works out in particular cases, the revolutionary will reject either the empiricist's conception of the privileged facts (usually the very idea that there is any such class of facts) or empiricist limitations on our knowledge-yielding means and capacities, and its idea of what they must work on, or both.

\section{PLATONISM}

How do we manage to think, or to speak, about the world at all-either truly or falsely? How can our thinking be about things? How, for example, can we say 'The lawn is green', and thus say what is so precisely and only if the lawn is green? An ancient form of answer has it that this is accomplished through mediation by something external both to us, and to whatever it is that we think about. Somehow we get in touch with the right mediators-how, exactly, need not concern us here. As it may be, we discern them, or mean them, or intend for them to mediate. However put in place, those mediators do their job quite 
independent of us: they sort possible arrangements of the world into those that are just what we thought, or said, and others. That general form of answer-that sort of reference to something external to us for setting the standards for things being as we thought, or said-is what I am here calling Platonism.

To use an old term, we might call the mediators universals. I call the lawn green. My words connect to a certain universal: greenness. The lawn, for its part, relates in its own way to that universal. To name that way, we might say the lawn partakes of the universal-or fails to. If it does partake, it is its way of being colored-its look-that makes that so. As for the universal, it decides, just by being the universal it is, what looks will constitute partaking in it, and what ones will not, so, thereby, whether the lawn partakes. Since it is connected to my words as it is, it decides how things must be for what I said to be true, or equally, when what I said would be true. And the way it does its work has nothing to do with us.

The term 'universal' is unfashionable. But vocabulary is not important. There are all sorts of ways of thinking of external mediators between us and the world which-thanks only to the mediation-makes our particular thoughts about it true or false. To take a thoroughly modern version, one might think that an English predicate-something like 'is green'-has a certain property which we can specify this way: it is true of something just in case that thing is green. It is no proper business of the semanticist how the predicate came by that property. The important thing is that it has it. To think of such a property just is to think of it as one that sorts out possible conditions of a thing into those that would make 'is green' a true description of it, and others-just the job universals were meant to do. As with universals, how this property does its work - what sorting out it does-has nothing to do with us.

Is Platonism true? Who, one might think, cares-except, perhaps, a philosopher, who, by definition, has nothing better to do. But philosophers only worry about problems people naturally worry about. It is just, or so we think, that we are best prepared to do that. The above idea of mediators-and the idea that there is any way for us to get connected to them-has carried the odor of myth to more than just professional philosophers. Retreating from it hastily, one may fall into the idea that there is really no objective talk about the world at all; just, as it is sometimes put, an ongoing conversation, which (some would say) might as well be about nothing at all, or nothing other than itself. As we know, many today have fallen for that. (Empiricism's role here shows in Richard Rorty's reliance on Quine in arguing for that reaction.) But to succumb to that idea is just to beat the wrong retreat. It is to remain with a mythological view of what objectivity would be like. That has proven, disastrous, notably, for the humanities. The revolution I am describing knows a better way. Or so I will suggest. 
Frege began his revolution with the injunction "always to separate the psychological from the logical, the subjective from the objective." ${ }^{2}$ As a research strategy, that idea has undeniably borne quite a lot of fruit: mathematical logic. But it has also been an understandable impetus to a form of Platonism. For, in Frege's hands, it encourages the idea that thoughts-the things we think-may be studied in splendid isolation from their thinkers; that such things as relations of entailment between thoughts, or facts, are determined by laws that do whatever they do entirely independent of us; that the domain of thoughts-that is, things there are to think-has an intrinsic physiognomy, no thanks to us. What is external to us here is a structure linking items in a domain-thoughts-reflected in structures intrinsic to the thoughts themselves. This structure determines in the first instance what follows from what. But, in doing that, it also determines how what we think may be, or fail to be, so.

Fregean Platonism depends on a particular picture of how logic, or in his terms, the laws of truth, applies to particular thoughts (and on treating 'thought' most seriously as a count-noun). The anti-Platonism in the twentieth century revolution is largely a reaction against this tendency in Fregean thought (where 'Fregean' covers much more here than Frege's thought itself). The change in ways of thinking from the Platonism that went along with the early development of logic to the anti-Platonism of the later Wittgenstein is captured in these two remarks by Wittgenstein, one as a central figure in the nineteenth century revolution (then spilled over into the twentieth), the second a later comment on the first:

Logic fills the world: the limits of the world are its limits.

Thus we cannot say in logic: Such and such there is in the world; that there is not.

For that would apparently presuppose that we exclude certain possibilities, and this cannot be the case, since otherwise logic would have to get outside the limits of the world; as if it could also consider these limits from the other side. ${ }^{3}$

The ideal, as we think of it, is unshakably fixed. You can never get outside it. You must always turn back. There is no outside at all; outside there is no air to breathe.-Where does this idea come from? It is just like a pair of glasses on our nose, through which we see whatever we look at. It never occurs to us to take them off. $^{4}$

To see how that encapsulates the revolution, we need to understand both remarks. We get an inkling of the point of the second if we note that it occurs just after an extended attack on Platonism occupying the first 92 paragraphs of the Investigations (where such famous notions as language game, and

\footnotetext{
${ }^{2}$ Gottlob Frege, The Foundations of Arithmetic, J. L. Austin, trans., Basil Blackwell, Oxford, 1950, Introduction, p. X.

${ }^{3}$ Tractatus Logico-philosophicus. 5.61.

${ }^{4}$ Philosophical Investigations, $\$ 103$.
} 
family resemblance, are first introduced). One main idea there is that we should not see facts of meaning, or of content-notably facts as to when things would be as we said-as governed by, and always deriving from, some definite set of rules. As put in $\S 81$,

In philosophy we often compare the use of words with games and calculi which have fixed rules, but we cannot say that someone who is using language must be playing such a game.

We can begin to appreciate the point of all that if we see just what the anti-Platonist picture of content is as it is developed in those 92 paragraphs. I will try to convey that here by laying out the picture as I have developed it myself, over the last twenty five years or so.

Suppose someone says, 'Jones has a desk in her study.' Jones is a poor student. In the room she uses for a study she has a door lain atop stacked milk crates. Is what was said true? A natural answer might be: it is if, but only if, she had a desk. But the question is, is what she had a desk? A reasonable answer would be: it depends on what you count as a desk. Which is to say: there is an understanding of what it is for something to be a desk (henceforth an understanding of being a desk) on which what she had is a desk; and another on which it is not. Neither understanding is incompatible merely with what it is to be a desk. Rather, what being a desk is permits either way of seeing things; either corresponds to a permissible way of looking at the question of something's being a desk. A note: when I say there is an understanding of being a desk on which what she had is one, all I mean is that counting what she had as a desk just is a permissible way of understanding what being a desk is. I am not thinking of an understanding of being a desk as something else from which that result derives.

Our destination requires one more piece. Being a desk, as such, admits of understandings. But a particular deployment of that notion, say, to describe, on a particular occasion, the way things are with Jones, may require some particular way of understanding being a desk, and exclude other such ways. Suppose we creditors have just attached all of Jones' furnishings, and have sent the sheriff for them. We are speculating as to what we might get for her furniture at the brocante market. We are pessimistic about the worth of her somewhat over-used futon. But, we think, there is still hope. Someone remarks, 'Well, she has a desk in her study.' But wrongly. All there is is a door and some milk crates. We will not get much for that.

We will return to this second piece. But first a brief digression. I chose this first example because it illustrates one salient feature of the meanings of the words we use, or at least many of them. What drives the wheels here is that there are many strands in what we would take 'desk' to mean; what we expect from it, or from a description of something as a desk. (By 'we', I mean we who are competent in that area of language if anyone is.) If we were to reflect on what a desk is, it would be reasonable to take a number of things as central to that notion. One would normally expect of a desk that it is an artifact; that it 
is made for writing on (and related activities); that it is used for writing on (and etc.); that, given its place in a certain tradition of furniture manufacture, there is a certain look and form that it would have (though, of course, we expect no strict account of the similarities that make for the right look and form). What is in Jones' study respects some of these strands. It is used for writing on. In one sense, it was made for writing on. That is why Jones assembled those bits in those ways. But that is certainly not standard furniture making. Nor is the result the standard image of a desk. So we face these questions: what relative importance should we attach to the strands that are honored here vis-a-vis the ones that are not? Just how insistent should we be that our normal expectations be satisfied before we count something as a desk? And where a strand is honored if you look at things in one way (if Jones' assembly of bits counts as manufacturing), but not if you look at things in another, just how should we look at things? If we put the facts of meaning in this way, then the point becomes that there is no uniquely right way of answering all these questions.

Another example presents another way of viewing the phenomenon. Suppose I point at the ink in a certain bottle and say, 'This ink is blue.' Suppose that ink has been designed to behave, in a certain respect, like blood. It is blue in the absence of oxygen, but turns red instantly on contact with it. And it is packaged in air-tight bottles. (The accountant's secret weapon.) So it contrasts with ink that looks blue in the bottle and writes blue as well. Now is what I said true? We can rehearse all the points made in the last case. There is an understanding of what it is (for ink) to be blue on which the ink is blue, and another on which it is not. Both are permissible as such. What I said may have been said on the one understanding (that is, I may have said what is so if the ink is blue on that understanding), or said on the other, or said on neither. So I might have stated truth, or falsehood, or neither. (We do not know the circumstances of my speaking.)

Here another aspect of meaning is to the fore. We can see it if we note a distinction between the color blue, and being colored blue. The color blue contrasts with the color red, for most purposes with the color green, and so on. We may have a perfectly secure idea of how to draw those distinctions. If asked which color a given color is, we have various techniques, or capacities, that allow us to give an answer. Those ways of distinguishing between colors form, as one might think of it, a core of techniques that may be used in classifying objects-as we would say, by the way they are colored. That core fits into an indefinitely diverse array of ways of classifying objects. Each of these constitutes, inter alia, a different understanding of being colored a given color. The core-our ways of distinguishing between colors-remains constant across all of these. It is what makes them all understandings of being blue, or green, or whatever. So we may think of meaning (as opposed to what is said in using words, or in words on a given use of them) as putting tools at our disposal, to be combined more or less ad lib with other tools for generat- 
ing ways of describing the way things are; but doing nothing in particular purely on their own.

So much for the digression. Now back to the main theme. Suppose we think of our words as connecting to universals (in whatever guise). Suppose, just for a moment, that we know how to name each one: their names are found in the ordinary vocabulary of English, with some scholastic nominalizations-blueness, for example. As Platonism has it, those universals mediate between us and the world we describe: with no help from us, they sort out cases where the world would be as we described from cases where it would not be. Well, we now see that that just is not so. As it may be, I said 'Jones has a desk', and spoke truth. But that does not follow from anything the universal deskness might accomplish on its own. For there are both understandings of being a desk on which Jones has one, and others on which she does not.

What Platonism must now suppose is that the universals with which our words connect are much more arcane than first seemed. Where I said 'Jones has a desk', there is, we must suppose, some particular universal-let us call it flurgness-such that what I said is true just in case some item in Jones' room partakes of that; and flurgness really does sort out cases in a unique way into ones of the world being as described in descriptions that connect with it and ones that are otherwise. (One might think of being flurg as being a desk on such and such understanding of being one.)

Just here, we revolutionary anti-Platonists-Wittgenstein, Austin, Putnam and $\mathrm{l}-$ get off the boat. With what right do we assume that there are such arcane mediators? Trivially, there would be if there were specifiable ways of understanding being blue, or being a desk, that do not themselves admit of understandings - if, for example, we can say what it is for something to be flurg in a way that leaves no two distinct and permissible understandings of what being that would be. But we have no reason to believe that. Perhaps desks may be made out of milk crates and doors. But if I take a standard manufactured desk and suspend it upside down from the ceiling, it is still, for most purposes, a desk. What if I suspend two strings of milk crates from the ceiling and tie a door to the bottom of each string. Is that a desk? Here we find new varieties of understandings of being one. And it does now seem that we have started on a process of discovery that may continue ad inf.

At this point human beings re-enter the picture. There is a long story as to how, and no time to tell it here. But here is the gist. Put us normal humans (with a tolerable degree of linguistic competence) in a normal situation, and some ways of understanding a description-of understanding being a desk, say-will strike us as reasonable, others as entirely unreasonable. That is just what I illustrated in making the second needed point. When Max described Jones as having a desk, the understanding of being a desk on which he did that just is that which is most reasonable, by human lights, in the circumstances of his so describing her. The anti-Platonist point now becomes: what we humans are prepared to recognize as to what is reasonable in particular 
situations (what we are prepared to see those situations as making reasonable, or unreasonable) is not reducible to the work that any specifiable universal might unequivocally do.

I have been emphasizing one variety of current anti-Platonism. Another important one deserves mention as well. It's motto might be Freud's, "we are not masters in our own house." Here the point is that it is not up to us to decide how our concepts will apply (or, if you prefer, what concepts they are to be). Rather, for any concept we might use, if it is of a way for the world, or items in it, to be, there must be room for the world to help decide, not just what fits the concept, but what it would be for something to fit. And once that room is left, a concept cannot be conjured into a platonic entity. Condensing drastically, any notion we can form of a way for things to be consists of many strands. The world can make these strands conflict. How the concept then applies depends on what it would be, given the way the world proves to be, to give each strand its proper due. A concept can contain no recipe for thus assigning due, or none that decides, no matter how the need for that might arise, how it is to be done. So how due is properly assigned must always be, in part, a matter of what is reasonable by human standards. The world might show, for example, that we can make no sense of a path in space doing all one would have thought a straight line ought to do, or at least not independent of a way of viewing it. It would thus make problems as to what would count as a straight line; how that concept then would apply. Giving the world its proper say here, we cannot suppose such questions settled by some platonic intermediary. Our present appreciation of that point is Hilary Putnam's main contribution to the revolution.

\section{IDEALISM}

Every revolution has its price. The price of this one is an apparent threat of idealism. Idealism, in brief, is the view that we, or our minds, or the mind, make up the world, to at least some extent; our thinking about the world, or our capacity for it, makes the world we think about (in part) the way it is. That is certainly the wrong way to think about things, say, when you are on the interstate and your tank is showing empty. Merely thinking about it differently won't help. There are, in fact, several different threats here. Since I see myself as standing with the revolutionaries, I am committed to those threats being only apparent. I wish I could prove that here (or anywhere). But I will hint at one main idea.

Anti-empiricism carries its own idealist menace. We speak, for example, of others' thoughts and feelings. Our talk makes sense if, supposing that it does, it is clear enough when the descriptions we thus deal in are rightly given. If it does make sense, then in engaging in it we really do describe the way things are (or are not). So there are facts as to, for example, who is happy and who is not. It is a feature of that sort of discourse that sometimes one can see that someone is happy. So, equipped the way we are, that is the 
sort of thing we are sometimes able to see. For all this to be so, talk about happiness (say) need not satisfy any other, external, requirement. Notably, the facts about happiness need not follow from other facts, equally available to a thinker who did not know what happiness was, by principles available to just any thinker at all. We can see some facts as to who is happy, because we are equipped to think of the world in terms of happiness. A rational Martian, for example, might not be so equipped. He would then just not see that feature in things (people) at all. That is the anti-empiricist idea.

It is part of the anti-empiricist idea, then, that the way we are designed to think opens our eyes to certain domains of fact. Specifically, our ability to detect happiness turns on a domain-specific capacity not necessarily shared by all thinkers. The question naturally arises, suppose we had been designed differently? Well, our eyes might be closed to those areas of reality. We would not find any such facts. But then, would there still be such facts? Or are such 'facts' just what our mind-design projects onto the world, an image our mind casts on things? The latter seems idealism.

This threat may be disarmed. Different organisms might be sensitive to different facts. That a given organism is unable to discern some facts that another can is no reason to think the other is not really discerning facts. The mere fact that we might have been designed differently does not show that the facts we can in fact discern would not have been facts but for our discerning them. Wittgenstein, while part of the nineteenth century revolution, provided a fitting image for this idea;

Let us imagine a white surface with irregular black spots. We now say: Whatever kind of picture these make I can always get as near as I like to its description, if I cover the surface with a sufficiently fine square network and now say of every square that it is white or black. ... This form is arbitrary, because I could have applied with equal success a net with a triangular or hexagonal mesh. ... To the different networks correspond different systems of describing the world. ${ }^{5}$

The way we are designed to think places a certain net against the world-the network of concepts we are equipped to use. Another design would have placed a different net. But that there might be different nets does not jeopardize the claim of a given one to fit.

One might still feel unease. To take a pointed case consider ethics. Suppose it really is wrong (other things equal) to step on babies, or to throw them in front of moving trains. So there are moral facts. We are equipped, in principle, to see what they are. And it is hard to see how the moral facts could extend farther than, or differ from, what we are in the end, prepared to recognize. (It is hard to assign sense to the idea that, say, tying your left shoe before your right one is really wrong, though no human being will ever be capable of seeing that it is.) In the end, on reflection, we find the idea compelling that it is wrong to tread on babies. Suppose we had been differently

\footnotetext{
${ }^{5}$ Tractatus Logico-Philosophicus, 6.341
} 
designed, so as to find nothing compelling in that idea. Would it still have been, for all that, wrong to tread? The hard part is that the facts here are blatantly ones as to what one is to do. It is hard to see how two such forms of mindedness could simply place different nets against such facts, either of which is a way of capturing them. If there are two such nets, the question is how either could be right.

In any event, anti-Platonism deprives us of this simple line of response. The anti-Platonist idea is that whether a given description one might give of things-say, a description of some blood, or, again, some ink, as blue-would fit the way things are depends, first, on the occasion of, or for, giving it, and, second, irreducibly on the reactions it would be natural for reasonable people to have in that situation-on some judgements as that, in such and such circumstances (selling ink to students, say), you ought not to call ink blue unless it will write blue, no matter how it looks when in the bottle. Anti-Platonism brings human beings - expressers and thinkers of thoughts-back ineliminably into the picture. The reverse side of that is that it cannot follow merely from the fact that Jones, say, described things truly, and Pia, say, did not that each gave a different description of things, or applied different concepts. Each might, for example, have described the same blood as blue, the one saying what is true given its present condition in the vein, the other what is untrue given its looks when oxygen is present. If the net is a system of concepts, they will not have applied different nets. Rather, each will have applied the same net differently. Wittgenstein's image does not show how to make sense of that.

Pia described some blood as blue. Given human ways of thinking, she thus described it truly. Had our ways of thinking been different, in intelligible ways, in giving that description she would not have described it truly. That is just what anti-Platonism comes to. (It is no anodyne view.) Blood that counted as blue might not have done so. It is an easy slide from that to the view that what is blue and what not depends on our reactions. That, of course, would be idealism.

Max, say, described some blood as blue-truly. Pia described that same blood as blue, but falsely. On the anti-Platonist idea, the difference lies in our ways of thinking of how descriptions need to fit the circumstances of their giving. On that idea misread, what is blue, and what not, depends on our ways of thinking. But to say that Max spoke truth and Pia falsehood is not to say that there is something - that blood-that is both blue and not. Rather, the blood is blue on one understanding, but not on another, of what it is for blood to be blue. Apart from understandings, and occasions for having them, there is no answer to the question what is blue and what is not. Or so the anti-Platonist maintains. So the misreading puts an answer in his mouth to a question which, on his view, simply cannot arise.

Max did what counted, where it counted, as describing blood as blue. If our minds do not create the world, then the blood must be the way he said it was, no matter how we think-so even where we would not call that blood 
blue. But where we would not say that of the blood, we also would not say that Max described it as what we would then understand by being blue. We then have other ways of saying what he said-that it looked blue without oxygen, say. Put it that way and the blood is-still counts as-the way he said it was. Paraphrase is crucial to our notion of a way for blood to be. (And paraphrase does not demand synonymy.)

Still, though, Max described something as blue-correctly, we would say. Different thinkers might find what he did not true describing. We might have been such different thinkers, had we been designed differently. In which case, it seems, Max would not have described truly. What now seems in jeopardy is the objectivity of judgement. Why should our own perceptions of describing, and of situations, count for more than the perceptions of such other thinkers? How can our perceptions make a judgement correct, when by other possible perceptions it would not be? Idealism could just as well have been taken to be the view that judgement is not objective as the view that the way the world is depends on the way our minds are. The one just amounts to the other.

Here one might cite Sextus Empiricus. Sextus suggests that different animals have different perceptions of color. He then says,

[l]f the same objects appear dissimilar depending on the variations among animals, then we shall be able to say what the existing object is like as observed by us, but as to what it is like in its nature we shall suspend judgement. ${ }^{6}$

Further,

If, therefore, appearances become different depending on the variations among animals, and it is impossible to decide between them, it is necessary to suspend judgement about external existing objects. ${ }^{7}$

The lawn looks green to us, but who knows how it looks to a cow? So it would be rash to judge that it is green.

One might respond to Sextus this way: 'What are we talking about when we talk about something being green? What is it for something to be green? However you understand that question, not something such that whether something is green or not is at all a question of how it looks to cows. Being green leaves cows out of the picture, and we are free to do likewise.' One might say: we do not converse with cows; our descriptions are not meant for them. That response seems fair.

Now let us turn to human and Martian thinkers. Max calls the ink blue, and that satisfies our standards of good description. For unfathomable reasons, it fails to satisfy Martian standards. But Max wasn't speaking to, or for, Martians. He was doing what he purported to do-what he presented himself as

\footnotetext{
${ }^{6}$ Outlines of Pyrrhonism, Book I, chapter 14, $§ 59$ (trans. By Julia Annas and Jonathan Barnes).

${ }^{7}$ Op. cit., $\$ 61$
} 
doing - if his words fit into human life as true words ought-if they have the uses for human beings that humans might (reasonably, by our standards) expect of them. If they are true, then they are a guide to certain sorts of human conduct; one on which we humans can rely (which give us no cause for complaint). Ink descriptions may be useful in activities of check signing, for example. One would assign them content they do not have in expecting more of them. Which is to say that, just as bovine perceptions play no role in deciding the correctness of our descriptions of things as green, Martian perceptions have no role in deciding whether Max described correctly. And if he did, then things are the way he said (a point, we have learned, that cannot always be put by saying: 'That ink (really) is blue').

\section{CODA}

In Investigations $\$ 242$ (for cognoscenti, the paragraph immediately before the notion of private language is introduced), Wittgenstein says,

Communicating in language presupposes agreement, not just in definitions, but (as odd as this may sound) in judgements. This appears to abolish logic, but does not.

Here Wittgenstein expresses sensitivity to the idealist fears his anti-Platonism might awaken. Why should there be so much as a false appearance of abolishing logic, and why should the appearance be false? We can understand his remark, I think, by returning to the contrasting quotes I used to encapsulate the shift from the nineteenth century revolution to the twentieth century one.

In the first remark, Wittgenstein thinks of logic as mapping the limits of thought, and thus of the world. Thoughts-the things there are to think, suppose, and so on-are thus its subject matter; what it is a science of. These thoughts, it is supposed, form a totality with a definite structure: for each thought there is such a thing as the way it relates to all the others. Logic's task is to describe that structure at a suitable level of generality. Against that background, anti-Platonism will seem to make human ways of thinking-natural human reactions, as the later Wittgenstein might put it-a determinant of what the logical facts are. For, on this view, if content is irreducibly a matter of how we human thinkers would see things, then so too is entailment. And it was just entailments that logic was meant to map. So human reactions make logic, which would, indeed, abolish it-the most profound and disturbing idealism imaginable.

The second quote, though, gives us another way of thinking of logic's appointed task. By that idea, logic is not (directly) the science of thoughts. Rather, it puts at our disposal a set of powerful tools we can use, as needed, to organize, and to systematize, thought. The tools are rigid, simply because that is how they are designed. It is a feature of them that certain relations between the organizing forms they put at our disposal are not up for grabs. 
That those relations hold depends on nothing, in just this sense: to imagine them not holding (if such were possible at all) would be to step outside the system, to abandon that tool. But how these tools grip onto the thoughts we wish to organize, and where they can get purchase at all, depends on the phenomenon of our thinking - on the material there is for them to work on. If given tools should prove unsatisfactory for given purposes, we might abandon them and construct new ones.

All that is metaphor, unsatisfactory for that reason and for others. I sympathize with anyone who finds these images disturbing. So there is more work to do. That is just the point I would like to leave you with. There is a reading of Wittgenstein on which his later philosophy does away with philosophical problems, and thus, in a sense, with philosophy itself. Such problems, on this reading, are to be thought of as mere pseudo-problems (even if sometimes deep for all that), to be dissolved rather than solved. If that is how the twentieth century panned out, the upshot is the dawn of 'post-philosophy', whatever that may be; philosophy is dead. Perhaps Wittgenstein encouraged this view of his later work. But by working through the changed view that it, and, more broadly, the twentieth century revolution represents, we have arrived at a batch of problems which certainly seem genuine, which are deep, and which even have a traditional cast.

Charles Travis

Dep. of Philosophy

Stirling University

Stirling, FK9 4LA, UK

ct2@stir.ac.uk 